\title{
O CAPITAL SOCIAL E SUAS IMPLICAÇÕES NA POLÍTICA DE ASSISTÊNCIA TÉCNICA E EXTENSÃO RURAL EM MATO GROSSO
}

\author{
E. M. ZAMBRA, P. A. R. SOUZA ${ }^{*}$ e S. R. COSTA \\ Universidade Federal de Mato Grosso - UFMT \\ pauloramalho@ufmt.br*
}

Submetido 01/10/2016 - Aceito 07/07/2018

DOI: $10.15628 /$ holos.2018.5130

\section{RESUMO}

A extensão rural é uma das estratégias de inclusão produtiva no programa Brasil Sem Miséria (BSM), por meio política de Assistência Técnica e Extensão Rural (ATER). Entretanto, a implementação da política em suas diferentes dimensões ainda é pouco discutida em algumas regiões, como no caso de Mato Grosso. Neste sentido, o objetivo geral desta pesquisa é analisar a política de Assistência Técnica e Extensão Rural (ATER) sob a ótica do Capital Social em Mato Grosso. Para tal, utilizou-se de uma estrutura metodológica com característica exploratória, a partir de dados de fontes bibliográficas, documentais e um processo estruturado de análise de conteúdo, com o intuito de discutir o fenômeno da pesquisa. Dentre as principais constatações, pode-se inferir que o desenvolvimento do capital social pode atuar como facilitador das ações de formação educacional e assistência técnica no meio rural em Mato Grosso. Por fim, a pesquisa identificou a necessidade de aprofundamento no entendimento de outras políticas dentro do BSM e seu efeito na eficácia e capilaridade da ATER em Mato Grosso.

PALAVRAS-CHAVE: Extensão Rural, Capital Social, Inclusão Produtiva, Políticas Públicas.

\section{SOCIAL CAPITAL AND ITS IMPLICATIONS IN TECHNICAL ASSISTANCE POLICY AND RURAL EXTENSION IN MATO GROSSO}

\begin{abstract}
The Rural extension is one of the productive inclusion strategies in the Brazil Sem Miséria (BSM) program, through a Technical Assistance and Rural Extension policy (ATER). However, the implementation of the policy in its different dimensions is still little discussed in some regions, as in the case of Mato Grosso. In this sense, the general objective of this research is to analyze the policy of Technical Assistance and Rural Extension (ATER) from the point of view of the Social Capital in Mato Grosso. For that, a methodological structure with exploratory characteristic was used, based on data from
\end{abstract}

\begin{abstract}
bibliographic sources, documentaries and a structured content analysis process, with the purpose of discussing the phenomenon of the research. Among the main findings, it can be inferred that the development of social capital can act as a facilitator of educational training and technical assistance actions in rural Mato Grosso. Finally, the research identified the need to deepen the understanding of other policies within the BSM and its effect on the effectiveness and capillarity of ATER in Mato Grosso.
\end{abstract}

KEYWORDS: Rural Extension, Social Capital, Productive Inclusion, Public Policy. 


\section{INTRODUÇÃO}

A extensão rural está fundamentada em princípios educacionais que visam levar ao meio rural e às famílias que nele residem, tecnologias e informações técnicas, econômicos, sociais, ambientais e políticas relacionadas à agricultura, pecuária, economia doméstica, sustentabilidade, entre outros (kawai et al., 2016; Noce \& Neto, 2017; Souza, Anjos, Pinheiro \& Machado, 2018)

Conforme Peixoto (2014, p. 904) “[...] entre os anos de 1990 e 2000, a comunidade científica e os formuladores de políticas públicas em pouco ou nada participaram dos debates internacionais sobre a reestruturação dos serviços de Ater no mundo" e, apesar das particularidades existentes no meio rural brasileiro, "[...] há um conjunto significativamente rico de experiências em sistemas e métodos de Ater desenvolvidas em diversos países. 0 conhecimento das trajetórias desses serviços é tão importante quanto o dos resultados das experiências internas para a discussão de estratégias e políticas de fomento aos serviços de Ater no Brasil".

Ao analisar os Programas e Políticas Federais direcionados à Agricultura Familiar no Brasil, conforme informações disponibilizadas pelo Ministério do Desenvolvimento Agrário (MDA) verifica-se que a Assistência Técnica e Extensão Rural é definida como uma política pública que visa levar assistência técnica às propriedades rurais, melhorar os processos no trabalho e, consequentemente, a qualidade de vida dos agricultores. Em complemento, observa-se que o eixo de Inclusão produtiva faz parte do plano Brasil sem Miséria (BSM) e trata-se de uma política pública social que visa contribuir com a redução da pobreza no meio rural e fomentar $\mathrm{O}$ desenvolvimento local.

Neste êxito, dentre as diferentes ações propostas para a implementação da inclusão produtiva no âmbito do BSM, a política de Assistência Técnica e Extensão Rural (ATER) agrupa um conjunto de atores locais, instituições públicas e apoiadoras, por meio de processos e relações de trocas diretas e indiretas.

Entretanto, as trocas entre atores e instituições presentes na política não são simétricas. Segundo Dorneles e Redin (2015, p. 02) "agricultores não mantém vínculos com associações ou as entidades representativas, tendem a ser excluídos dos benefícios concedidos na execução dos projetos de cooperação técnica". O que evidencia a dificuldade no trânsito de informações entre os atores da política.

Para tal, alguns autores (Coleman, 1988; Putnam, 1996; Fukuyama, 1995; Souza, Romeiro \& Zambra, 2014; Alves \& Friedrich, 2017; Ramos \& Prates, 2017) evidenciam o papel do capital social como "azeitador" de relações sociais oriundas de processos de interação entre atores locais e instituições.

Neste sentido, dentre outras questões a serem discutidas nesta pesquisa, seu objetivo geral foi analisar a política de Assistência Técnica e Extensão Rural (ATER) sob a ótica da teoria do Capital Social em Mato Grosso. 


\section{REVISÃO BIBLIOGRÁFICA}

O referencial teórico buscou, por meio da utilização de um arcabouço de estudos teóricos e empíricos, apresentar os conceitos e reflexões com o intuito de subsidiar a construção dos procedimentos metodológicos e a discussão dos resultados identificados na pesquisa.

2.1 A Política de Assistência Técnica e Extensão Rural (ATER) no contexto do Plano Brasil sem Miséria (BSM)

As políticas públicas (policy) são uma das resultantes da atividade política (politics): compreendem o conjunto das decisões e ações relativas à alocação imperativa de valores envolvendo bens públicos. Ainda complementa dizendo que ações e decisões privadas, ainda que de interesse público não se confundem com atividade política e com atividade pública (Rua, 2009).

Nesse meio, as Políticas públicas sociais são "desdobramentos e até mesmo respostas e formas de enfrentamentos - em geral setorializadas e fragilizadas - as expressões multifacetadas da questão social do capitalismo, cujo fundamento se encontra nas relações de exploração do capital sobre o trabalho" (Behring \& Boschetti, 2008, p. 51).

Para o enfrentamento da questão social, o Estado utiliza-se da assistência social, através de instituição de programas e ou ações compensatórias com o intuito de amenizar as desigualdades sociais. Além da instituição de políticas sociais, cria ainda os mecanismos responsáveis pela prestação de serviços assim como os critérios para atendimento da população classificada como pobres, carentes e desamparadas (SPOSATI, 1989),

No período recente, os Programas de proteção social no Brasil têm apresentado efeitos consistentes na redução da pobreza e desigualdade entre grupos vulneráveis. Em 2 de junho de 2011, foi lançado o Plano Brasil Sem Miséria (PBSM) com o objetivo de erradicar a extrema pobreza no Brasil até 2014. O Plano articula mais de 120 ações distribuídas em 20 ministérios e é coordenado pelo Ministério do Desenvolvimento Social e Combate à Fome (MDS) (PAES-SOUZA, 2013; Alves, 2017).

O Plano Brasil sem Miséria (PBSM) adota o enfoque multidimensional, ao reunir um conjunto de ações que visam combater as diferentes dimensões da extrema pobreza, cobrindo desde o acesso a transferências monetárias, até o acesso a serviços públicos e a oportunidades de emprego e renda (BRASIL, 2013).

Apesar de adotar a renda como indicador de extrema pobreza, o PBSM adota uma estratégia multidimensional de ação, reunindo cerca de 100 ações distribuídas em três grandes eixos estruturantes de atuação: garantia de renda, acesso a serviços e inclusão produtiva. Em síntese, o eixo estruturante 'garantia de renda' engloba programas de transferências monetárias para alívio imediato da situação de extrema pobreza, onde a principal ação é o Programa Bolsa Família. No eixo 'acesso a serviços' estão os programas de promoção do acesso a serviços públicos de bem-estar social e fortalecimento da cidadania, bem como a ampliação das unidades responsáveis por tais serviços. Por fim, o eixo estruturante 'inclusão produtiva' visa retirar as famílias da situação de miséria ao inseri-las no mundo do trabalho (Brasil, 2013). 
Neste estudo, o objeto de discussão encontra-se no eixo estruturante de 'inclusão produtiva', que tem o objetivo de ampliar as oportunidades de trabalho e renda para a população mais pobre. Para melhor atender às especificidades do mercado de trabalho das grandes cidades e do meio rural, foram definidas duas estratégias de melhoria das condições de inserção econômica do público do Brasil sem Miséria: uma rota para a inclusão produtiva no meio urbano e outra para a inclusão produtiva rural, a qual será enfatizada no decorrer deste contexto (Brasil, 2014; Mattei, 2017)

Os programas voltados à rota de inclusão produtiva urbana oferecem cursos de qualificação para trabalhadores, acesso a postos de trabalho, formalização e sustentabilidade para empreendedores de baixa renda e oportunidades de expansão dos negócios e empreendimentos. Os programas da rota de inclusão produtiva rural visam o fortalecimento da produtividade e comércio dos agricultores familiares por meio de repasses para investimentos na pequena produção agrícola, bem como por meio da compra de alimentos da agricultura familiar e assistência em conhecimentos técnicos (Brasil, 2013; Costa, Souza \& Almeida, 2018).

Especificamente, na rota de inclusão produtiva rural, encontram-se as políticas de Assistência Técnica e Extensão Rural (ATER); Programa de Aquisição de Alimentos (PAA) e demais programas como Água para Todos, Bolsa Verde e apoio a assentados e acampados, conforme apresentado no Quadro 01.

Quadro 01: Eixo de inclusão Produtiva Rural do BSM

\begin{tabular}{|c|c|c|c|c|}
\hline Tipo & Programa/Ação & Objetivo & Público-Alvo & Órgão Gestor \\
\hline \multirow{4}{*}{$\begin{array}{l}\text { Inclusão } \\
\text { Produtiva } \\
\text { Rural }\end{array}$} & $\begin{array}{l}\text { Assistência técnica } \\
\text { e Extensão Rural } \\
\text { (ATER) e Fomento }\end{array}$ & $\begin{array}{l}\text { Melhorar a situação } \\
\text { nutricional das famílias e } \\
\text { gerar excedentes para } \\
\text { que gerem renda }\end{array}$ & $\begin{array}{l}\text { Agricultores familiares, } \\
\text { quilombolas, indígenas, } \\
\text { extrativistas e pescadores } \\
\text { artesanais em extrema } \\
\text { pobreza, do Cadastro Único } \\
\text { portadores da Declaração de } \\
\text { Aptidão ao Pronaf (DAP). }\end{array}$ & $\begin{array}{l}\text { MDS e Ministério do } \\
\text { Desenvolvimento } \\
\text { Agrário (MDA) }\end{array}$ \\
\hline & $\begin{array}{c}\text { Programa de } \\
\text { Aquisição de } \\
\text { Alimentos (PAA) }\end{array}$ & $\begin{array}{l}\text { Estimula a articulação } \\
\text { entre a produção da } \\
\text { agricultura familiar e as } \\
\text { demandas locais. }\end{array}$ & $\begin{array}{l}\text { Agricultores familiares, } \\
\text { assentados da reforma agrária, } \\
\text { extrativistas, pescadores } \\
\text { artesanais, e demais } \\
\text { comunidades tradicionais. }\end{array}$ & $\begin{array}{l}\text { MDS, MDA e Fundo } \\
\text { Nacional de } \\
\text { Desenvolvimento da } \\
\text { Educação (FNDE) }\end{array}$ \\
\hline & $\begin{array}{c}\text { Programa Água } \\
\text { para Todos }\end{array}$ & $\begin{array}{c}\text { Garantir amplo acesso à } \\
\text { água potável para as } \\
\text { populações rurais. }\end{array}$ & $\begin{array}{c}\text { Famílias rurais que não têm } \\
\text { acesso ou têm acesso precário } \\
\text { à água de qualidade, do } \\
\text { Cadastro Único, e com renda } \\
\text { per capita de até } \mathrm{R} \$ 140 .\end{array}$ & $\begin{array}{l}\text { MDS e Ministério da } \\
\text { Integração Nacional } \\
\text { (MI) }\end{array}$ \\
\hline & $\begin{array}{c}\text { Programa Bolsa } \\
\text { Verde }\end{array}$ & $\begin{array}{l}\text { Desenvolvimento } \\
\text { ambientalmente } \\
\text { sustentável com inclusão } \\
\text { social por meio do } \\
\text { depósito de R\$ } 300 \\
\text { trimestrais }\end{array}$ & $\begin{array}{l}\text { Famílias residentes em } \\
\text { florestas nacionais e reservas, } \\
\text { ribeirinhos e demais } \\
\text { comunidades tradicionais } \\
\text { extremamente pobres } \\
\text { inscritas no Cadastro }\end{array}$ & $\begin{array}{l}\text { Ministério do Meio } \\
\text { Ambiente (MMA) }\end{array}$ \\
\hline
\end{tabular}

Fonte: adaptado de Brasil-MDS (2013). 
Pensando nisso, foi estabelecida uma rota de inclusão produtiva para as famílias do meio rural com base nas ações do Ministério do Desenvolvimento Agrário (MDA) e do Instituto Nacional de Colonização e Reforma Agrária (Incra). A rota de inclusão produtiva foi concebida de forma a ser implementada como uma "esteira" em que os pequenos produtores fossem atendidos com várias políticas de apoio à produção, como pode ser visualizado na Figura 1 (BRASIL, 2014).

Com o intuito de melhorar a produção, além de ações de infraestrutura de acesso à água e energia por meio dos programas Água para Todos (MI, MDS, MS e MMA) e Luz para Todos (MME), foi criada uma ação específica mais adequada à realidade das famílias de agricultores familiares em condições de maior vulnerabilidade (mais pobres). Essas famílias, em sua maioria, produzem em pequenas propriedades, possuem baixo aporte tecnológico na produção e dificuldades no acesso aos programas de crédito, necessitando de uma combinação de assistência técnica e extensão rural (Ater) e recursos de fomento para investir na melhoria da produção familiar (Brasil, 2014).

Por este motivo, surgiu o Programa de Fomento às Atividades Produtivas Rurais, de responsabilidade do MDA e do MDS, em que foram incorporados: a) um novo modelo de assistência técnica individualizada por, no mínimo, dois anos, mais adequada às especificidades da população rural de agricultores familiares em extrema pobreza e, b) recursos não reembolsáveis para que os produtores pudessem investir em projetos produtivos elaborados em conjunto com os técnicos de ATER (Brasil, 2014).

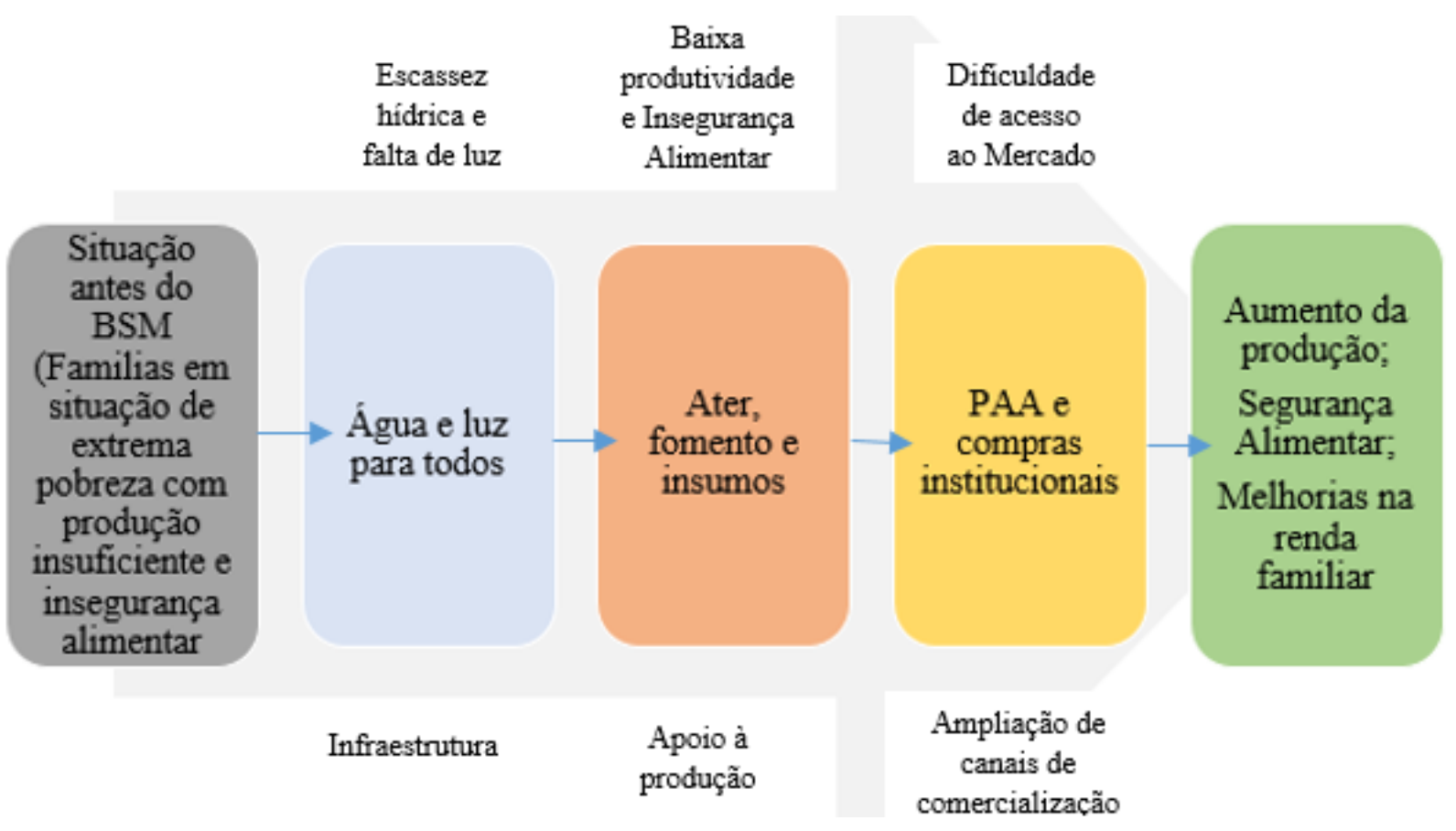

Figura 1: A inclusão produtiva dentro da política BSM Fonte: Brasil MDS (2014).

No caso da comercialização da produção excedente, aparecia como a maior estratégia a ampliação do Programa de Aquisição de Alimentos (PAA), implementado pelo MDS, pelo MDA e 
pela Conab, atendendo a algumas demandas específicas: a expansão para as regiões Norte e Nordeste, a inclusão de compras de organizações produtivas de mulheres e de Povos e Comunidades Tradicionais e também o estímulo para que mais produtores em extrema pobreza fizessem parte das cooperativas e organizações que já vendiam parte da sua produção para o PAA. (Brasil, 2014).

Os serviços de Assistência Técnica e Extensão Rural - ATER, foram iniciados, no país, no final da década de quarenta, no contexto da política desenvolvimentista do pós-guerra, com o objetivo de promover a melhoria das condições de vida da população rural e apoiar o processo de modernização da agricultura, inserindo-se nas estratégias voltadas à política de industrialização do país. A ATER foi implantada como um serviço privado ou paraestatal, com o apoio de entidades públicas e privadas. Posteriormente, com apoio do governo do presidente Juscelino Kubitschek, foi criada, em 1956, a Associação Brasileira de Crédito e Assistência Rural - ABCAR, constituindo-se, então, um Sistema Nacional articulado com Associações de Crédito e Assistência Rural nos estados (Brasil, 2007).

Em meados da década 1970, o governo do presidente Ernesto Geisel "estatizou" o serviço, implantando o Sistema Brasileiro de Assistência Técnica e Extensão Rural - SIBRATER, coordenado pela EMBRATER e executado pelas empresas estaduais de ATER nos estados, as EMATER. Como parte dos programas de ATER daquela época, durante mais de uma década, a participação do Governo Federal chegou a representar, em média, $40 \%$ do total dos recursos orçamentários das EMATER, alcançando até $80 \%$, em alguns estados (Brasil, 2007).

Em 1990, o governo do presidente Collor de Mello extinguiu a EMBRATER, desativando o SIBRATER e abandonando claramente os esforços antes realizados para garantir a existência de serviços de ATER no país. As tentativas de coordenação nacional por meio da Empresa Brasileira de Pesquisa Agropecuária - EMBRAPA e, posteriormente, pelo Ministério da Agricultura não foram capazes de evitar que as EMATER ficassem à mercê das políticas de ajuste estrutural e das difíceis condições financeiras dos respectivos estados, além de se ver ampliada a influência dos interesses políticos dominantes em cada região sobre os destinos das entidades oficiais de ATER. A consequência desse processo de afastamento do Estado e diminuição da oferta de serviços públicos de ATER ao meio rural e à agricultura aparece, hoje, evidenciada pela comprovada insuficiência destes serviços em atender à demanda da agricultura familiar e dos demais povos que vivem e exercem atividades produtivas no meio rural. Com isso, restringem-se as possibilidades de acesso das famílias rurais ao conhecimento, aos resultados da pesquisa agropecuária e a políticas públicas em geral, o que contribui para ampliar a diferenciação a exclusão social no campo (Brasil, 2007).

Para Caporal e Costabeber (2004, p. 150)

A crítica ao extensionismo convencional se iniciou com Paulo Freire, nos anos 60, e teve seu auge no período da Nova República, com o chamado Repensar da Extensão Rural. Esta crítica ganhou novos contornos nos anos 1990, quando passaram a se destacar duas grandes correntes: a da privatização e/ou transferência do serviço (e recursos) de assistência técnica e extensão rural (ATER) para o terceiro setor (ONGs, OCIPs, municipalização, etc.) e aquela que seguirá defendendo a necessidade de uma extensão rural pública, gratuita e de qualidade para a agricultura familiar (que se consolidou no Workshop Nacional de ATER, promovido pela FASER, ASBRAER, CONTAG, FAO e MA, em 
1997). Já no final da década de 1990, estava claro que era insuficiente, senão desnecessária, uma ATER pública para transferir os mesmos pacotes tecnológicos aos agricultores. Inúmeros estudos também mostravam que o papel do Estado no desenvolvimento rural precisava ser outro, estimulando outras formas de desenvolvimento e estilos de agricultura de base ecológica compatíveis com os preceitos da sustentabilidade. Ademais, as lições do passado mostravam que a metodologia de intervenção no processo de desenvolvimento rural deveria pautar-se pelo respeito às experiências históricas, valores culturais e éticos, assim como às diversidades étnicas e ambientais das comunidades rurais.

Em 2003, o Ministério do Desenvolvimento Agrário - MDA passou a ser responsável pelas atividades de Assistência Técnica e Extensão Rural - Ater, como estabelece o Decreto № 4.739, de 13 de junho daquele ano. Por delegação da Secretaria da Agricultura Familiar - SAF, um grupo de técnicos coordenou a elaboração da nova Política Nacional de Assistência Técnica e Extensão Rural - PNATER, promovendo um amplo processo de consulta, a partir de audiências, encontros e seminários envolvendo representações dos agricultores familiares, de movimentos sociais e de prestadoras de serviços de Ater governamentais e não governamentais (Caporal, 2006).

A lei de ATER é a Lei no 12.188 sancionada em 11 de Janeiro de 2010, que institui a Política Nacional de Ater - PNATER e de Reforma Agrária e o Programa Nacional de Assistência Técnica e Extensão Rural na Agricultura Familiar e Reforma Agrária - PRONATER e altera a Lei 8.666 de 21 de Junho de 1993. A ATER é um serviço de educação não formal em que agentes capacitados auxiliam agricultores familiares, quilombolas, indígenas, extrativistas e pescadores artesanais para que melhorem suas atividades produtivas. A assistência técnica promove o aperfeiçoamento do sistema de produção das unidades produtivas familiares, aumentando a quantidade, a qualidade e o valor de seus produtos. Assim, as famílias podem ter bons alimentos para consumo próprio, melhorando sua situação nutricional, e gerar excedentes para comercializar, melhorando sua renda e qualidade de vida. De maio de 2011 a setembro de 2014, 3.800 famílias de agricultores familiares do estado, distribuídas em 20 municípios, tiveram o acesso a serviços de ATER garantido por meio de chamadas públicas para a seleção de instituições especializadas na prestação desses serviços, contratadas com recursos do Ministério do Desenvolvimento Agrário.

De acordo com Brasil (2014, p. 56-7),

no caso da inclusão produtiva rural, para além da alta incidência de pobreza verificada no campo, onde um quarto da população estava em situação de extrema pobreza em 2010, o diagnóstico da situação produtiva dos mais pobres apontava um quadro geral de famílias com produção insuficiente e em situação de insegurança alimentar, provocadas pela confluência de fatores como a falta de infraestrutura necessária que viabilizasse a produção, incluindo falta de água e energia elétrica. Por outro lado, a produção dessas famílias de agricultores familiares ${ }^{1}$ era caracterizada por baixa produtividade e por dificuldades de comercialização do excedente. Nesse sentido, para melhorar as suas condições de vida, era necessário aumentar e qualificar a produção, gerando efeitos diretos na qualidade da alimentação de seus membros e também, no caso das famílias

\footnotetext{
${ }^{1}$ A lei no 11.326, de 24 de julho de 2006, que estabelece os conceitos, princípios e instrumentos destinados à formulação da Política Nacional da Agricultura Familiar e Empreendimentos Familiares Rurais, considera agricultor familiar e empreendedor familiar rural, aquele que trabalha em estabelecimento dirigido pela família; obtém renda predominantemente oriunda deste estabelecimento; possui área de terras que não ultrapassem quatro módulos fiscais e que utilizam mão-de-obra predominantemente familiar (...) (BRASIL, 2006).
} 
que obtivessem excedentes de produção, que fosse ampliado o acesso aos canais de comercialização, como forma de geração de renda.

Conforme Castilhos (2002, p. 61):

A emergência de políticas públicas e as ações do Estado em prol da agricultura familiar, no Brasil, a partir de meados da década de noventa, é decorrente deste contexto macroeconômico que a reforma do Estado imprime no período recente. São dois os fatores principais que motivam o surgimento destas políticas públicas, mais consolidadas e estruturadas do que as anteriores, para a agricultura familiar [...] A primeira tem a ver com a crescente necessidade de intervenção estatal frente ao quadro crescente de exclusão social [...] A segunda justificativa para a ascensão da agricultura familiar enquanto objeto de políticas públicas é provocada pelo fortalecimento dos movimentos sociais rurais no Brasil.

As experiências, com acertos e erros em políticas públicas (e sociais) desenvolvidas ao longo dos últimos vinte anos, especificamente aquelas voltadas aos agricultores familiares, apontam que é necessário intensificar as estratégias para reversão do êxodo rural e permanência sustentável de famílias no meio rural. Para Rocha e Branderbuerg (2003, p. 05):

A trajetória da modernização na agricultura teve como consequência um dos mais graves desajustes sociais já vistos na história da humanidade. A modernidade causou no setor agrícola ambiguidades antagônicas, principalmente em países periféricos, como o Brasil, pois ao mesmo tempo em que proporcionou melhores condições tecnológicas para produção e um consequente aumento de produtividade, fez com que ocorresse um processo de exclusão humana avassalador, o êxodo rural. Diante disso, o que se observa "no campo" é que apenas os velhos e os jovens "ficaram," os primeiros por não terem mais perspectivas e os segundos por "ainda" não encontrarem condições para transferirem-se para as cidades.

Pode-se dizer que o desenvolvimento local é resultado da participação dos beneficiários (agricultores familiares), através de iniciativas comunitárias, parcerias com o Estado (nos três níveis) e com empresas privadas. Está baseado nas potencialidades dos recursos humanos, institucionais e naturais do chamado capital social. Este é o cenário em que políticas públicas de desenvolvimento se fundem com o social para valorizar as diferenças e conquistar qualidade de vida e ambientes sustentáveis. Uma estratégia desenvolvida para combater a exclusão social, no meio rural, é a incorporação de recursos tecnológicos de baixo custo, através de ações associativas ou comunitárias que otimizam os ganhos, com a compra e venda em comum, a barganha de melhores preços ou a criação de sistemas condominiais de coleta e transporte e, em alguns casos, industrialização dos produtos. Porém, esta estratégia somente terá sucesso se for ancorada em políticas públicas de apoio financeiro e técnico, de qualificação profissional e de infraestrutura (Gehlen, 2004).

\subsection{0 processo de desenvolvimento da agricultura familiar em territórios rurais}

A partir da década de 1990 tanto a agricultura Familiar quanto o Desenvolvimento Rural ganham força no cenário político e econômico, também no meio acadêmico. Nesse momento, o discurso sobre o rural apoiado em estudos realizados em todo o mundo, geraram novos conceitos e orientações.

Nas duas últimas décadas, vem ocorrendo um processo de construção da categoria agricultura familiar, a agricultura como modelo e os grupos de agricultores como identidade 
política (Picolotto, 2011). Os estudos passam mostrar a importância social e econômica, a capacidade produtiva, a diversidade e que a agricultura familiar foi a grande responsável pelo desenvolvimento da produção de alimentos no Brasil e em muitos países desenvolvidos e deixa de buscar somente a condições precárias e de inferioridade desse segmento enfatizado nos anos anteriores.

Abramovay (1998) e Veiga (1998) veem vantagens sociais, ambientais e econômicas no modelo de organização da agricultura familiar, sendo esse diversificado, democrático, sustentável e eficiente. O agricultor familiar como personagem político é recente na história brasileira, a categoria se apresenta como novidade no cenário nacional tendo uma trajetória de lutas marcada por conflitos sociais e políticos (Picolotto, 2011).

Picolotto (2011) evidencia o processo de reconhecimento da agricultura familiar nos anos 90 com a criação de políticas públicas de incentivos aos agricultores familiares (como o Programa Nacional de Fortalecimento da Agricultura Familiar - PRONAF, em 1995), secretarias de governo orientadas exclusivamente para trabalhar com a categoria (como a Secretaria da Agricultura Familiar criada em 2003 no âmbito do Ministério do Desenvolvimento Agrário, criado em 1998), a Lei da Agricultura Familiar promulgada em 2006, a qual reconheceu oficialmente a categoria, foram criadas novas organizações de representação sindical com a intenção de fortalecer a identidade política de agricultor familiar (como a FETRAF) e a elaboração de um caderno sobre a Agricultura Familiar com dados do Censo Agropecuário de 2006 (IBGE, 2009) contribuiu para salientar a importância social e principalmente econômica desta categoria de agricultores no país.

Os estudos do Projeto de Cooperação Técnica com Guanziroli et al., (1996) e Guanziroli e Cardim (2000), também tem grande importância na classificação e definição do conceito de agricultura familiar e mudança para um enfoque teórico positivo. Um primeiro estudo realizado no ano de 1994 teve como objetivo declarado: elaborar diretrizes para "uma nova estratégia de desenvolvimento rural para o Brasil". Dentre as suas principais contribuições fez uma sugestão de classificação dos estabelecimentos agropecuários brasileiros em dois modelos: um "patronal" e outro "familiar". Outros estudos tiveram a importância de mostrar qual a participação social e econômica da agricultura familiar no setor agropecuário brasileiro e na definição de critérios operacionais de classificação do que seria a agricultura familiar e a patronal. Vários estudos, livros e pesquisas no início da década de 1990 sobre o deslocamento teórico e conceitos em relação a agricultura familiar ganharam grande projeção devido sua vinculação ao projeto FAO/INCRA

Uma mudança de enfoque e entendimento sobre desenvolvimento rural começa a ganhar força na década de 1990, antes associado a tentativas do Estado e dos organismos internacionais em substituir fatores de produção considerados atrasados nas regiões rurais pobres (Navarro, 2001).

A nova abordagem teve como contexto o processo de estabilização da economia, no terceiro ano da década de noventa os índices inflacionários baixos abriram espaço para propostas de mudança social. A partir de 1993-94 entraram em vigor muitas das regulamentações estabelecidas pela nova constituição de 1988, os municípios com a descentralização política e financeira passam ser responsáveis pela execução de grande parte das políticas públicas. Organizações e movimentos sociais retornam ao cenário político com novas ideias e de forma 
atuante. Outro aspecto relacionado é a incorporação da noção de sustentabilidade e meio ambiente, a qual gerou repercussões importantes sobre o Estado, as instituições, os intelectuais e mediadores políticos (Schneider,2010)

Schneider (2010), em sua abordagem, o que denomina de estratégias de sobrevivência familiares e a diversificação dos modos de vidas rurais, mostra que na maioria das vezes as iniciativas e ações que geram impactos na melhoria das condições de vida e a ampliação das perspectivas de garantir a reprodução social e econômica estão nas próprias localidades e territórios onde vivem. A diversificação não está apenas para a obtenção de rendas, mas combinada com estratégias garantem a reprodução social, econômica e cultural. O autor prefere definir o desenvolvimento rural como um conjunto de ações e práticas que visam reduzir a pobreza em áreas rurais e estimular um processo que empodera (empowerment) os habitantes rurais possibilitando a eles definir e controlar suas prioridades para a mudança.

Vale destacar o rápido interesse despertado sobre a abordagem territorial no Brasil, especialmente no âmbito dos planejadores e formuladores de políticas públicas, evidenciado na criação de uma Secretaria de Desenvolvimento Territorial, ligada ao Ministério do Desenvolvimento Agrário (MDA), e na adoção do tema por outros órgãos governamentais. Enfoque territorial adotado já nos anos 1990 internacionalmente e presenciado em uma série de programas de pesquisas e iniciativas políticas, como a criação da divisão territorial da OCDE em 1994. E em 1996 o Banco Mundial publica seu relatório A nova visão do desenvolvimento rural, no qual o intuito é justamente uma tentativa de mostrar as mudanças ocorridas no meio rural nas últimas décadas e a necessidade que elas traziam em substituir o enfoque setorial por um de caráter territorial (Favareto, 2010).

A origem do enfoque territorial, conforme Schneider (2010), está em dois processos distintos. Primeiro, pelo desgaste da noção de desenvolvimento promovido pelo esgotamento teórico e prático da abordagem regional influenciado pelo neoliberalismo em contraposição as perspectivas keynesianas em vigor desde o final da Segunda Guerra Mundial. A noção de região como unidade de referência torna-se limitada para as políticas públicas e ações para a promoção do desenvolvimento rural. Nesse período, as noções de sustentabilidade ambiental e qualidade de vida passam vigorar nos novos critérios sobre desenvolvimento. $O$ segundo fator está baseado nas transformações econômicas, no crescente questionamento sobre dinâmica setorial, os quais se desenvolveram mais a partir de uma lógica de escopo do que de escala.

No meio rural a noção de território adquire importância sobre o desenvolvimento voltar-se a um conjunto de protagonistas e a superar um âmbito estritamente setorial, tendo a diversificação das economias rurais como resultado mais importante em áreas não densamente povoadas. E a dependência fundamentada na relação do indivíduo com o espaço em que vive (Abramovay, 2003).

A abordagem territorial na perspectiva do desenvolvimento rural assume a função de uma ferramenta para se pensar o planejamento e a intervenção no tecido social a partir de alguma escala, seja ela local, regional, etc. O território passaria a ser uma unidade de referência, um nível de operação e agregação adequado para operar o planejamento de ações governamentais e 
políticas públicas que promovam mudanças e transformações múltiplas no espaço social (Schneider, Mattei \& Cazella, 2004).

\section{PROCEDIMENTOS METOdOLÓGICOS}

Quanto ao método, trata-se de uma pesquisa exploratória tem o objetivo de familiarizar um assunto ainda pouco conhecido e pouco explorado, tendo como objetivo principal o aprimoramento de ideias ou a descoberta de intuições. Seu planejamento é bastante flexível, devido à pouca informação sobre o fato estudado (Gil, 2002).

Para a coleta de dados foram utilizadas as técnicas: bibliográfica e documental. A técnica de pesquisa bibliográfica é fundamentada em material já elaborado, principalmente de livros e artigos científicos. Tem como vantagem, o acesso a uma maior quantidade de informação e dados em comparação a pesquisa direta (Gil, 2002). Através de livros, teses e artigos científicos publicados em periódicos são utilizados para a construção do referencial teórico. A técnica de pesquisa documental é similar à pesquisa bibliográfica, diferencia-se na natureza das fontes, a qual utiliza-se de documentos de "primeira mão", que não receberam nenhum tratamento analítico e de fontes de dados secundários, dados que alguma vez já foram analisados (Gil, 2002). A análise dos dados foi desenvolvida por meio da técnica de análise de conteúdo, com o intuito de apresentar as discussões acerca das implicações do capital social na política de assistência técnica rural em MT (Vergara, 2009).

\section{RESULTADOS E DISCUSSÕES}

\subsection{O capital social como indutor da política ATER em Mato Grosso}

Ao mencionar a necessidade de bem-estar para populações rurais, um conjunto de defensores dos efeitos positivos das relações sócias em comunidades, vilarejos e regionais, tomam por base dimensões de construção e análise de políticas que derivam do capital social.

Neste sentido, a definição de capital social discutida pode por Coleman (1988) o apresenta como um emaranhado de recursos sócio estruturais relacionados ao ativo principal dos indivíduos dos grupos inseridos dentro da comunidade, no qual três dimensões estão presentes: confiança, canais de interação e arcabouço de normas e sanções. De Souza et al. (2014, p. 04) descreve as três dimensões de Coleman (1988) como sendo:

1. O nível de confiança está relacionado com o nível de extensão das estruturas existentes na comunidade, na qual a maior densidade do capital social está atrelada a altos níveis de confiança entre os atores locais;

2. A existência de canais de interação fomenta o fluxo de informação gerando sinergia e a novas ideias na comunidade.

3. As normas e sanções encorajam os indivíduos a trabalhar por um bem comum abandonando interesses próprios e imediatistas.

Indo ao encontro da discussão de Coleman (1988), Putnam (1996) define o Capital Social como o envolvimento individual em atividades coletivas, possibilitando a configuração de redes de confiança recíprocas estruturadas no centro do grupo ao qual o indivíduo está inserido de maneira 
a fomentar o civismo destes agentes. Esta relação produz externalidades positivas, por meio da atuação dos agentes envolvidos, gerando políticas efetivas voltadas para o sucesso institucional.

De Souza et al. (2014), na tentativa de ilustrar a evolução das discussões de Capital Social, estabelece uma evolução das pesquisas relacionadas com a teoria do Capital Social, as quais datam do ano de 1832. O Quadro 02 apresenta a evolução do conceito de Capital Sociais.

\section{Quadro 02: Evolução do Capital Social}

\begin{tabular}{|c|c|}
\hline AUTOR/ANO & CONCEITO \\
\hline Tocqueville -1832 & $\begin{array}{c}\text { Comparou relações associativistas em organizações voluntárias na França e } \\
\text { nos Estados Unidos, não usa o termo Capital Social, mas é considerado o } \\
\text { primeiro a discutir a temática. }\end{array}$ \\
\hline Hanifan - 1916 & $\begin{array}{l}\text { Os grupos sociais se beneficiam das relações mutuas, com foco no bem-estar } \\
\text { social. }\end{array}$ \\
\hline Jacobs - 1960 & $\begin{array}{l}\text { O Capital Social é acumulado de forma lenta e constante e pode ser } \\
\text { potencializado por meio da diversidade de atores. }\end{array}$ \\
\hline Granovetter - 1973 & $\begin{array}{l}\text { Retrata as redes sociais e a importâncias do capital gerado por meio das } \\
\text { interações dos indivíduos. }\end{array}$ \\
\hline Burdieu - 1980 & $\begin{array}{l}\text { Estudou a Sinergia gerada por meio da agregação de recursos com as redes } \\
\text { de atores sociais. }\end{array}$ \\
\hline Coleman - 1980 & $\begin{array}{l}\text { O Capital Social se desenvolve em redes densas ou fechadas às quais tem por } \\
\text { base o desenvolvimento de uma estrutura social e do auto interesse. }\end{array}$ \\
\hline Putnam - 1990 & $\begin{array}{l}\text { Discute o Capital Social com base em sua pesquisa que compara casos da } \\
\text { Itália e dos Estados Unidos. Sua pesquisa tem por base Confiança, coesão } \\
\text { social, participação, gerando conexões e redes sociais. }\end{array}$ \\
\hline Fukuyama - 2000 & Discute aspectos Culturais e o Capital Social como foco na economia \\
\hline Lin - 2001 & $\begin{array}{l}\text { Suas discussões são pautadas no estudo de relações que geram benefícios } \\
\text { entre os atores. O Capital Social é um benefício de quem o detém. }\end{array}$ \\
\hline Banco Mundial 2003 & $\begin{array}{l}\text { O Capital Social está relacionado aos atores locais e a produção do bem-estar } \\
\text { social. }\end{array}$ \\
\hline Vale 2006 & O Capital Social influencia diretamente o desenvolvimento organizacional \\
\hline
\end{tabular}

Fonte: De Souza et al. (2014).

As discussões de Coleman (1988), Putnam (1996) e De Souza et al. (2014), demostram o capital social como uma ferramenta multidimensional que emana das relações dos indivíduos social e geograficamente próximos. Esta perspectiva defendida pelos autores, evidenciou a possibilidade do entendimento da política da ATER em suas dimensões (Desenvolvimento Rural, Educação e Assistência Técnica) em Mato Grosso Sob a perspectiva da teoria do capital social.

A capacidade do capital social em gerar externalidades das relações entre atores sociais, como conhecimento, confiança, transferência de informação, normais e benefícios da interação entre ator local e as redes de suporte (atores/instituições), são argumentos que ligam a temática com a temática da ATER. Para tal, se faz necessária a efetiva articulação local, por meio de ações coletivas na concepção e implementação da maioria dos projetos de políticas sociais voltadas para o meio rural. 


\subsection{Desenvolvimento rural em Mato Grosso}

Os estudos existentes sobre capital social têm proporcionado ampla evidência de sua penetração e oferecem relevantes ensaios sobre sua influência política, econômica e social. Assim, evidencia-se que a instituição da Política Nacional ATER da pode também lançar mão deste recurso para sua efetiva implementação em Mato Grosso.

De acordo com as alegações do Banco Mundial (2003, p, 32.), "evidências crescentes mostram que a coesão social e o capital social são fundamentais para a redução da pobreza e o desenvolvimento regional". Essas afirmações reforçam o possível efeito positivo do fomento ao capital social em conjunto com a política da ATER.

Neste sentido, o conceito de o capital social deve ser integrado no processo de construção da política ATER em Mato Grosso, podendo influenciar positivamente na concepção e execução de projetos de desenvolvimento rural relacionadas ao combate à pobreza, extensão rural, política de crédito e outras atividades de desenvolvimento nas relações entre atores e instituições locais.

Entretanto, cabe ressaltar que em Mato Grosso, conforme dados do Censo do Sistema Único de Assistência Social (Censo SUAS), foram registrados em 2013 a existência de 112 Secretarias Municipais de Assistência Social Exclusivas (Brasil, 2015). A não existência destas Secretarias em 29 municípios pode influenciar negativamente no desenvolvimento da política. Este cenário pode dificultar a canalização das ações de desenvolvimento nos municípios não atendidos pelas secretarias.

\subsection{Formação educacional e assistência técnica}

Entre a população rural, a existência de níveis de educação formal elevados pode ser transformada em vantagem econômica para região. Segundo Chell (2001) atores com maiores níveis de formação tendem a desenvolver propriedades mais lucrativas. No mesmo sentido, Westhead e Matley (2006) defendem que políticas destinadas a aumentar a formação de habilidades e competências, pode auxiliar o desenvolvimento de pequenos negócios, como no caso da agricultura familiar em Mato Grosso.

Neste contexto, em Mato Grosso, a busca por transferência de conhecimento, formação e assistência técnica não são demandas recentes, parcerias institucionais entre INCRA/FAO objetivaram, na década de 90 , a condução de processos de formação e aperfeiçoamento técnico/produtivo de agricultores do Estado.

Assim, a busca de instituições políticas do estabelecimento de parcerias em Mato Grosso com foco na formação de atores locais, acentua o que Putnam (1996) denomina de dimensão política de uma população, na forma de um legado de tradições de cooperação, comportamento e confiança.

Conforme dados do Boletim "O Brasil sem Miséria em seu Estado", divulgado pelo Ministério do Desenvolvimento Social e Combate à Fome, no que se refere à Assistência Técnica e Extensão Rural (ATER), de maio de 2011 a abril de 2015, 321 famílias de agricultores familiares do 
estado de Mato Grosso tiveram o acesso a serviços de ATER, distribuídas em somente um (1) município.

Com foco no desenvolvimento da educação ou a formação em nível de extensão rural de agricultores, Lin (2001) acredita que a existência de capital social em uma região ou localidade está diretamente ligada ao processo de formação de habilidades e competências de um indivíduo. O autor destaca a natureza hierárquica de capital social em tornar os indivíduos com níveis de educação ou competências mais elevadas mais atrativas e, portanto, mais influentes no desenvolvimento da agricultura, como no caso de MT.

Para tal, tendo por base as afirmações de Lin (2001), o capital social pode ser fonte de aumento da educação e as competências na economia rural é clara, o que evidencia seu efeito na mitigação das desigualdades.

Resgatando o conceito de redes de conhecimento descrito por Coleman (1988), pode-se ressaltar que a inserção de atores em um ambiente de aprendizagem contínua, a partir do capital social, acarreta em um melhor aproveitamento de habilidades associados às competências pessoais, tais como comunicação e confiança.

Este processo tende a ser facilitado pelo capital social, pois os agricultores tendem a aprender a aprender. Corroborando com Coleman (1988) e Weick (1996), os quais descrevem que a exposição à educação torna os indivíduos mais confortável em um ambiente de aprendizagem.

No caso do desenvolvimento da educação e da assistência técnica na política ATER em Mato Grosso, a qual é parte integrante do Programa BSM, o fomento ao capital social por parte das instituições públicas e privadas estaduais pode influenciar positivamente o processo de indução do conhecimento na política local.

\section{CONCLUSÃO}

O desenvolvimento desta pesquisa teve por objetivo central analisar a política de Assistência Técnica e Extensão Rural (ATER) sob a ótica do Capital Social em Mato Grosso.

Ao evidenciar as características da política ATER, parte integrante do programa Brasil Sem Miséria (BSM), pode-se perceber sua centralidade em duas dimensões, sendo a primeira a dimensão da formação educacional e assistência técnica voltada para extensão rural e a dimensão do desenvolvimento rural, na qual são realizadas ações voltadas para implementação de tecnologias informacionais e sociais e a transferência para os atores locais de processos de produção com foco na inclusão produtiva.

Com base na questão do capital social discutido nesta pesquisa pode-se perceber seu papel na possível facilitação das ações de formação educacional e assistência técnica no meio rural, tanto por seu ambiente propício à aprendizagem e ao conhecimento endógeno, quanto pelos benefícios da comunicação e confiança, oriundos da organização dos atores em rede. 
Por outro lado, na dimensão de desenvolvimento rural, evidenciou-se a importância da concepção de políticas integradas e o efeito positivo da presença de instituições apoiadoras (públicas e privadas) na gestão da política da ATER, no caso de Mato Grosso.

Por fim, a pesquisa identificou a necessidade de aprofundamento no entendimento das interações entre de outras políticas dentro do programa Brasil Sem Miséria (BSM), na gestão e implementação da política da ATER, por meio de suas características multidimensionais e o efeito de outras políticas estaduais, que poderiam ampliar sua efetividade e capilaridade da ATER em Mato Grosso.

\section{REFERÊNCIAS}

Abramovay, R. (2003). O futuro das regiões rurais. Porto Alegre: UFRGS.

Abramovay, R., \&Veiga, J. E. (1998). Novas instituições para o desenvolvimento rural: o caso do Programa Nacional de Fortalecimento da Agricultura Familiar (Pronaf). Brasília: Ipea.

Alves, A. C. D. (2017). As práticas extensionistas da EMATER frente à política nacional de assistência técnica e extensão rural: um estudo na microrregião de Pará de Minas/Mg. Revista de Extensão e Estudos Rurais, 6(2), 26-44.

Alves, F. D., \& Friedrich, D. B. (2017). O necessário empoderamento do cidadão à efetivação das políticas públicas no brasil: a contribuição do capital social à efetiva participação nos instrumentos democrático-participativo-deliberativos. Revista de Direito da Cidade, 9(2), 725753.

Banco Mundial. (2003). Questionário integrado para medir capital social. Recuperado de: http://www.contentdigital.com.br/textos/comunidades/Questionario/

Behring, E. R, \& Boschetti, I. (2008). Política Social: fundamentos e história. (5a ed.). São Paulo: Cortez.

Brasil. (2006). Lei № 11.326, de 24 de julho de 2006. Estabelece as diretrizes para a formulação da Política Nacional da Agricultura Familiar e Empreendimentos Familiares Rurais. Brasília: Diário Oficial da União.

Brasil. (2007). Ministério do Desenvolvimento Agrário. Política Nacional de Assistência Técnica e Extensão Rural. Brasília: Ministério do Desenvolvimento Agrário /SAF/Dater.

Brasil. (2013). Ministério do Desenvolvimento Social e Combate à Fome. Caderno de Estudos do Curso de Indicadores para Diagnóstico do SUAS e do Plano Brasil sem Miséria. Brasília, DF: Ministério do Desenvolvimento Agrário; Secretaria de Avaliação e Gestão da Informação; Secretaria Nacional de Assistência Social.

Brasil. (2014). Ministério do Desenvolvimento Social e Combate à Fome. O Brasil sem miséria. Brasília: Ministério do Desenvolvimento Agrário, 2014.

Caporal, F. R. (2006). Política Nacional de Ater: Primeiros passos de sua implementação e alguns obstáculos e desafios a serem enfrentados. In: Tavares, J.; Ramos, J. (Org.). Assistência Técnica e Extensão Rural: Construindo o conhecimento Agroecológico. Manaus: Bagaço. 
Caporal, F. R., \& Costabeber, J. A. (2004). Agroecologia e Extensão Rural: Contribuições para a Promoção do Desenvolvimento Rural Sustentável. Brasília: Ministério do Desenvolvimento Agrário /SAF/Dater.

Castilhos, D. S. B. (2002). Capital Social e Políticas Públicas: um estudo da linha infra-estrutura e serviços aos municípios do PRONAF. Dissertação (Mestrado em Desenvolvimento Rural). Faculdade de Ciências Econômicas, Universidade Federal do Rio Grande do Sul.

Chell, E. (2001). Entrepreneurship: Globalization, Innovation and Development. London: Thompson Learning.

Coleman, J. (1988). Foundations of Social Capital Theory. Cambridge: Harvard University Press.

Costa, R. Z. D., Souza, P. M., \& Almeida, L. F. (2018). Agricultura familiar e associativismo: a experiência dos agricultores do município de Brejetuba-ES. Revista Desenvolvimento Social, 1(22), 19.

Dasgupta, P. (2000). O progresso econômico e a ideia de o capital social. In: Dasgupta, P., Serageldin, I. Capital Social: Uma Perspectiva Multifacetado. Washington: Banco Mundial, pp. 325-424.

De Souza, P. A. R., Romeiro, M. C., \& Zambra, E. M. (2014). Capital social organizacional e a produção científica no Brasil na área de administração de 2003 a 2013. Revista Internacional de Investigación en Ciencias Sociales, 10(2), 169-180.

Dorneles, R. M. A., \& Redin, E. (2015). A prática extensionista-análise dos projetos de ATER no Rio Grande do Sul. Acta Geográfica, 8(17), 33-49.

Favareto, A. (2010). A abordagem territorial do desenvolvimento rural-mudança institucional ou" inovação por adição"?. Estudos avançados, 24(68), 299-319.

Fukuyama, F. (1995). Social capital and the global economy. Foreign Affairs, 74(5), 89-103.

Gehlen, I. (2004). Políticas públicas e desenvolvimento social rural. São Paulo em Perspectiva, 18(2), 5-103.

Gil, A. C. (2002). Como elaborar projetos de pesquisa. (4a ed.). São Paulo: Atlas.

Guanziroli, C. E., Cardim, S. E. C. S. (Org). (2000). Novo Retrato da Agricultura familiar: O Brasil redescoberto. Brasília: INCRA/FAO.

Guanziroli, C. E., Romeiro, A., Di Sabbato, A., Shiki, S., \& Couto, V. (1996). Perfil da agricultura familiar no Brasil: dossiê estatístico. Brasília: INCRA/FAO.

Ibge. (2009). Censo Agropecuário 2006 - Agricultura Familiar: Primeiros resultados. Rio de Janeiro: IBGE.

Kawai, F. Y., Alves, M. P., Costa, S. R., Souza, P. A. R., Zambra, E. M., \& Andrade, J. R. (2016). A extensão rural voltada à agricultura sustentável como alternativa de combate à pobreza em assentamentos rurais no município de Rosário Oeste-MT, Brasil. Revista Espacios, 37(01), 118.

Lin, N. (2001). Social Capital: a theory of social structure and action, Cambridge: Cambridge University Press.

Mattei, L. (2017). O papel e a importância da agricultura familiar no desenvolvimento rural brasileiro contemporâneo. Revista Econômica do Nordeste, 45(5), 83-92. 
Navarro, Z. (2001). Desenvolvimento rural no Brasil: os limites do passado e os caminhos do futuro. Estudos Avançados- Dossiê Desenvolvimento Rural, 15(43), 83-100.

Noce, M. A., \& Neto, J. A. F. (2017). Uma análise da política pública brasileira de desenvolvimento rural, com foco no combate à pobreza no campo. Revista Cadernos de Ciências Sociais da UFRPE, 1(8), 36-56.

Paes-Sousa, R. (2013). Plano Brasil Sem Miséria: Incremento e mudança na política de proteção e promoção social no Brasil. IPC-IG Working Paper, 1(113), 01-69.

Peixoto, M. (2004). Mudanças e desafios da extensão rural no Brasil e no mundo. In: BUAINAIN, A. M. et al. O mundo rural no Brasil do século 21: A formação de um novo padrão agrário e agrícola. Brasília-DF: Embrapa.

Picolotto, E. L. (2011). As mãos que alimentam a nação: agricultura familiar, sindicalismo e política. Tese (Doutorado em Ciências do Desenvolvimento). Instituto de Ciências Humanas e Sociais, Universidade Federal Rural do Rio de Janeiro.

Putnam, R. D. (1996). Comunidade e Democracia: a experiência da Itália moderna. Rio de Janeiro. Editora: FGV.

Ramos, S. M., \& Prates, A. M. M. C. (2017). O Plano Brasil sem Miséria e o combate à pobreza no Município de Guarapuava-PR. Libertas, 17(1), 65-90.

Rocha, J. M., \& Branderbueg, A. (2003). Limites e desafios da agricultura familiar: a sustentabilidade em questão. REDES, 8(2), 93-104.

Rua, M. G. (2009). Políticas Públicas. Florianópolis: EdUFSC.

Schneider, S. (2010). Situando o Desenvolvimento rural no Brasil: o contexto e as questões em debate. Revista de Economia Política, 30(3), 511-531.

Schneider, S., Mattei, L., \& Cazella, A. (2004). Histórico, caracterização e dinâmica recente do Pronaf. In: Schneider, S., Silva, M. K., \& Marques, P. E. M. (Org.). Políticas públicas e participação social no Brasil rural. Porto Alegre: UFRGS, pp. 21-50.

Souza B. G., Anjos A. H., Pinheiro, C. E. F., \& Machado, M. G. (2018). Produção de alimentos e emancipação feminina: uma experiência de um grupo de mulheres na agricultura familiar. Revista Desenvolvimento Social, 1(22), 1-12.

Sposati, A. O. (1989). A Assistência Social na Trajetória das Políticas Sociais Brasileiras. (4a ed.). São Paulo: Cortez.

Tocqueville, A. Voyages aux États-Unis. Paris: Éditions Gallimard, 1932.

Veiga, J. E. (1998). A face territorial do desenvolvimento: Relatório de pesquisa. São Paulo: Fapesp.

Vergara, S. C. (2009). Projetos e relatórios de pesquisa em Administração. (10a ed.). São Paulo: Atlas.

Weick, J. (1996). Drop your tools: an allegory for organizational studies. Administrative Science Quarterly, 41(2), 301-313.

Westhead, P., \& Matley, H. (2006). Skills associated with employment positions in SMEs and favourable attitudes toward self-employment: longitudinal evidence from students who participated in the Shell Technology Enterprise Programme. Technology Analysis \& Strategic Management, 18(1), 93-124. 